\title{
EXAMINATIONS OF SELECTED THERMAL PROPERTIES OF PACKAGES OF SiC SCHOTTKY DIODES
}

\author{
Damian Bisewski ${ }^{1)}$, Marcin Myśliwiec ${ }^{2)}$, Krzysztof Górecki'), Ryszard Kisiel' ${ }^{2}$, \\ Janusz Zarębski ${ }^{1)}$ \\ 1) Gdynia Maritime University, Faculty of Electrical Engineering, Morska 83, 81-225 Gdynia, Poland \\ (d.bisewski@we.am.gdynia.pl, $\triangle$ k.gorecki@we.am.gdynia.pl, +48585586448,zarebski@am.gdynia.pl) \\ 2) Warsaw University of Technology, Institute of Microelectronics and Optoelectronics, Nowowiejska 15/19, 00-665 Warsaw, Poland \\ (sabatczarownic@gmail.com,r.kisiel@elka.pw.edu.pl)
}

\begin{abstract}
This paper describes the study of thermal properties of packages of silicon carbide Schottky diodes. In the paper the packaging process of Schottky diodes, the measuring method of thermal parameters, as well as the results of measurements are presented. The measured waveforms of transient thermal impedance of the examined diodes are compared with the waveforms of this parameter measured for commercially available Schottky diodes.
\end{abstract}

Keywords: Schottky diodes, transient thermal impedance, thermal measurements, silicon carbide, packaging.

C) 2016 Polish Academy of Sciences. All rights reserved

\section{Introduction}

Silicon carbide is a high-temperature semiconductor material, which theoretically can operate at temperatures considerably exceeding the silicon devices' operating temperatures $\left(150^{\circ} \mathrm{C}\right)[1-3]$. However, the value of maximum operating temperature given by manufacturers of silicon carbide semiconductor devices does not exceed $250^{\circ} \mathrm{C}$ [4], and typical values of this temperature for Schottky diodes made of silicon carbide produced by such companies as: Cree, GeneSiC, Infineon Technologies, Microsemi, RHOM, STMicroelectronics, USCi, Mitsubishi Electric, Fujielectric, are placed within the range from 150 to $175^{\circ} \mathrm{C}$ [5-7]. Obtaining higher values of the operating temperature is limited by the package construction. A package itself should be resistant to a high temperature created by the high-power operation of semiconductor structure as a result of the self-heating phenomenon [8-10]. This phenomenon is a result of converting the electrical energy generated in a given structure onto heat in non-ideal cooling conditions of this structure $[8,9]$.

The ability of removing heat generated in an electronic device can be characterized - among others - by the thermal resistance $R_{t h}$ or the transient thermal impedance $Z_{t h}(t)[11,12]$. The values of these parameters depend on the construction of cooling system of the device $[8,13,14]$, the device case being its essential component $[14,15]$.

Warsaw University of Technology undertook examinations that led to a construction of a package for SiC Schottky diodes that would be resistant to high temperatures [16]. The measurements of thermal properties: the thermal resistance and the transient thermal impedance of packaged SiC Schottky diodes have been recently performed at Gdynia Maritime University. They are carried out with the classical electric pulse-method [11]. Operation of these diodes in different cooling conditions is tested. The forced and free cooling are used and different values of the ambient temperature are examined. 
In the paper the considered diodes are described, next the measurement method and the measurement set-up are presented and, finally, the measurement results of thermal parameters of two types of silicon carbide Schottky diode packages are shown. On the basis of the measurement results practical usefulness of the considered packages is discussed.

\section{Tested diodes}

The chip structures of the examined $\mathrm{SiC}$ diodes were developed and manufactured in the Institute of Electron Technology, Warsaw. The diode chips were assembled in the laboratories of Institute of Microelectronics and Optoelectronics, Warsaw University of Technology. In the paper the results of measurements of a diode without a ceramic lid (CC1), two fully encapsulated diodes with ceramic lids (CB3, CB4), and a commercially available silicon MBR2060CT diode in the standard TO-220 package are presented.

The detailed information about the construction of the tested diodes is published in [16]. The measured current-voltage characteristics of the diodes CB3 and CB4 are presented in Fig. 1.

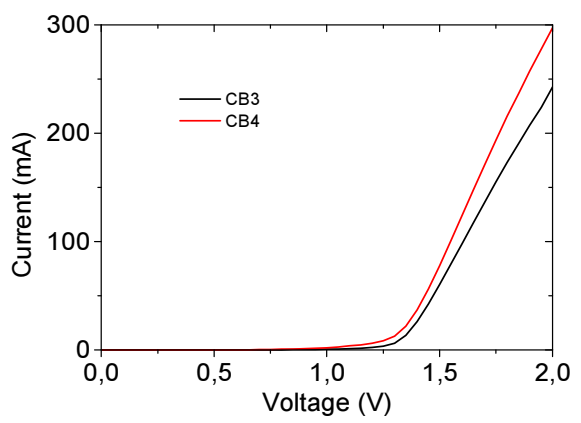

Fig. 1. The measured current-voltage characteristics of the diodes CB3 and CB4.

The shape of characteristics of two diode chips CB3 and CB4 were not the same before the assembling procedure. It is possible that - due to a defect in the $\mathrm{SiC}$ structure - the diode CB3 was more vulnerable to damage during a high-power stress [16]. Another reason for a diode failure may be - inherent in the package - inefficient heat removal from the device structure.

The structure with a ceramic lid enclosure and photographs of the tested devices are presented in Figs. 2 and 3.

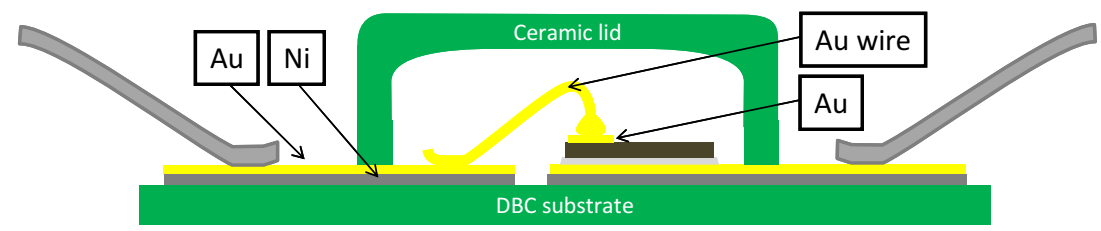

Fig. 2. The structure of enclosure with a ceramic lid.

Each tested structure is mounted on a ceramic DBC substrate $\left(\mathrm{Al}_{2} \mathrm{O}_{3}\right)$ coated on both sides with a $200 \mu \mathrm{m}$ copper layer. The top side of substrate is covered with a $3 \mu \mathrm{m}$ galvanicallyapplied nickel layer and a $1.5 \mu \mathrm{m}$ gold layer. The $\mathrm{SiC}$ structure is assembled into a package using the silver micro-powder sintering technique. The $\mathrm{SiC}$ structure top contact is connected 
to the package pads by four $50 \mu \mathrm{m}$ diameter gold wires. The structures are encapsulated using the SG705 glass. The lid is made of $\mathrm{Al}_{2} \mathrm{O}_{3}$ ceramic, the same as the DBC substrate. Its diameter is $10 \mathrm{~mm}$ and its height is $3 \mathrm{~mm}$.

Leads of the diodes have the form of copper strips $2 \mathrm{~mm}$ wide and $30 \mathrm{~mm}$ long. These leads are coated with a thin layer of silver. The results of measurements of the tested diodes' characteristics at temperatures of up to $350^{\circ} \mathrm{C}$ do not show a loss of performance of the diodes [16].

a)

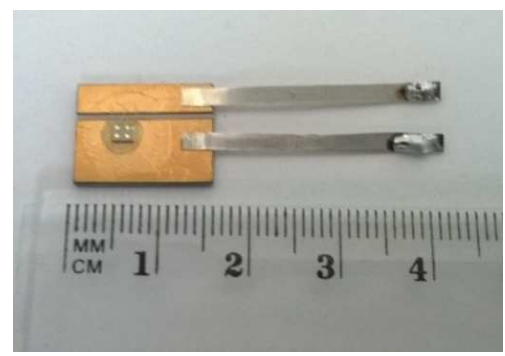

b)

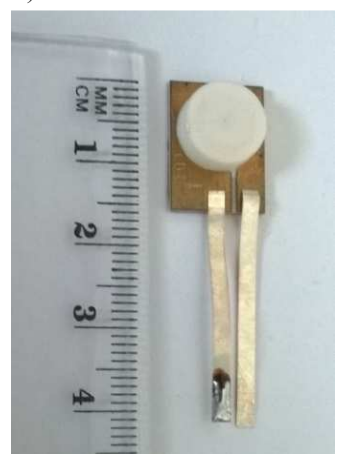

Fig. 3. Photographs of the tested diodes: a) without a ceramic lid; b) with a ceramic lid.

\section{Measurement method}

In order to evaluate the thermal properties of examined packages, the measurements of transient thermal impedance waveforms of the diodes have been performed. The classical electric pulse-method described in $[11,14]$ was used. This method is also used for measurements of thermal properties of bipolar and unipolar transistors .

The transient thermal impedance is determined using the indirect electrical method described in [14]. With this method the cooling curve of tested diode is measured. The voltage drop on the forward biased diode at a constant current is used as a thermally-sensitive parameter. The measurements of the forward voltage drop at a constant current $\left(I_{M}=30 \mathrm{~mA}\right)$ as a function of temperature show that the thermometric characteristic $v_{D}(\mathrm{~T})$ is linear within a wide temperature range for SiC Schottky diodes. The slope $F$ of this characteristic is calculated and its value is equal to about $-1 \mathrm{mV} / \mathrm{K}$.

The measurements were performed in three steps (calibration, heating and cooling) using the measurement set-up shown in Fig. 4.

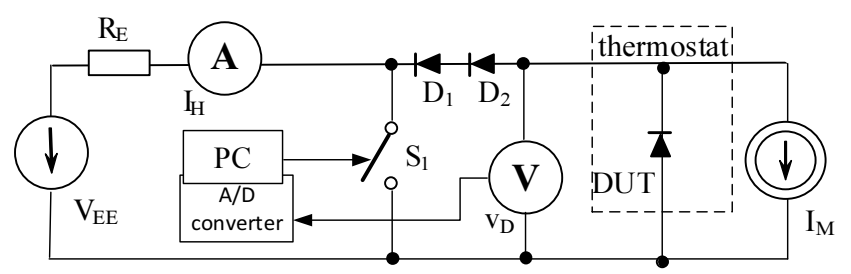

Fig. 4. A block diagram of the measurement set-up for measuring the transient thermal impedance of the diode.

In the measurement set-up the source $I_{M}$ delivers the measuring current of the examined diode (DUT) placed inside the thermostat. The voltage source $V_{E E}$ with the resistor $R_{E}$ sets 
the heating current $I_{H}$ measured by the ammeter. The switch $S_{1}$ (constructed with a power MOS transistor) is controlled by the PC. The position of switches depends on the measurement step.

In the calibration and cooling steps the switch $S_{1}$ is closed, whereas in the heating step it is opened. The diodes $D_{1}$ and $D_{2}$ protect the current source $\mathrm{I}_{\mathrm{M}}$ against short-circuit when the switch $\mathrm{S}_{1}$ is closed. The values of the voltage $v_{D}$ of the DUT are recorded using a 16-bit USB-1608GX$2 \mathrm{AO} \mathrm{A} / \mathrm{D}$ converter manufactured by Measurement Computing. The maximum sampling rate of the converter is $500 \mathrm{kS} / \mathrm{s}$.

At first, the calibration curve $v_{D}(\mathrm{~T})$ is measured. In this step the current $I_{M}$ flows through the DUT and the temperature in the thermostat is being slowly changed. Next, for a selected value of the thermostat temperature the tested diode is heated by a high power during its operation in the forward mode. This step ends when the steady device thermal state is achieved. The values $V_{H}$ of the voltage drop $v_{D}$ across the diode and $I_{H}$ of the diode current are recorded. The cooling step starts at time $t=0$ when the switch $S_{1}$ is closed and the tested diode is forward biased by a small current $I_{M}$. In this step the measurement results of the diode forward voltage $v_{D}(\mathrm{t})$ are recorded until it achieves its steady state.

The waveforms of transient thermal impedance are calculated using the following formula:

$$
Z_{t h}(t)=\frac{v_{D}(t=0)-v_{D}(t)}{F \cdot V_{H} \cdot I_{H}} .
$$

The obtained waveforms of $Z_{t h}(t)$ are typically approximated using [17, 18]:

$$
Z_{t h}(t)=R_{t h} \cdot\left[1-\sum_{i=1}^{N} a_{i} \cdot \exp \left(-\frac{t}{\tau_{t h i}}\right)\right],
$$

where: $R_{t h}$ - the thermal resistance; $\tau_{t h i}$ - the $i$-th thermal time constant; $a_{i}$ - the weighting factor of thermal time constant; $N$ - the number of thermal time constants. The values of parameters existing in (2) can be estimated in an easy way using the algorithm described in [19].

\section{Measurement results}

In order to enhance the component of thermal parameters characterizing the heat transfer from the semiconductor structure to the package, the forced water cooling system of the diodes is applied. The cooling system contains an Nexxxos XT145 copper cooler together with four ventilators of the diameter $120 \mathrm{~mm}$, an Aquastream XT pump and heat exchangers, as shown in Fig. 5. The cooling system contains the cooling EK-Ekoolant liquid. The system elements are connected by means of wavy lines of the diameter equal to $10 \mathrm{~mm}$. It is possible to regulate the flow speed of cooling liquid within the range from 0 to $150 \mathrm{dm}^{3} / \mathrm{h}$. This system makes it possible to obtain a constant value of the device case temperature [20]. The examined diodes are mounted with thermally-conductive glue to the liquid heat-sinks, which are the elements of the cooling system.
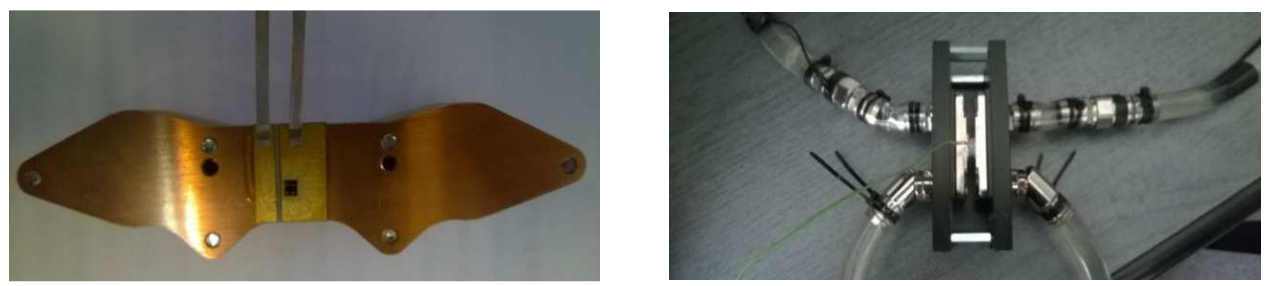

Fig. 5. Photographs of the examined diodes mounted to the liquid heat-sinks. 
Using the measurement method described in Section 3 the transient thermal impedance waveforms of the tested diodes are measured. The measurements are performed for diodes in two types of packages denoted as $\mathrm{CC} 1$ (without a lid) and $\mathrm{CB} 3$ and $\mathrm{CB} 4$ (with a lid). Additionally, the same measurements are performed for the commercial MBR2060CT diode type in the TO-220 package.

In Fig. 6 the measured transient thermal impedance waveforms of the examined elements are presented. Those characteristics are obtained at a different power dissipated in the examined diodes. The maximum power is limited by the critical forward current $(5 \mathrm{~A})$ of examined diodes.

a)

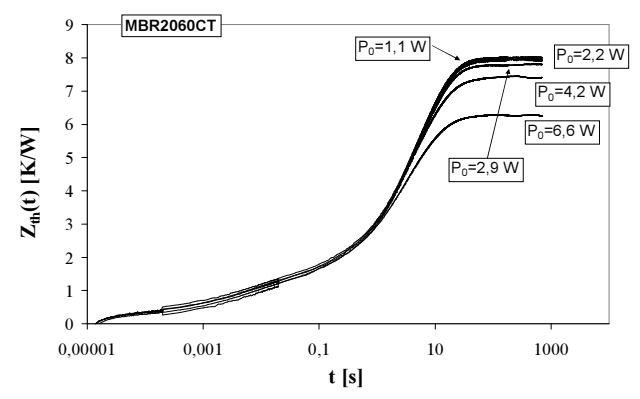

c)

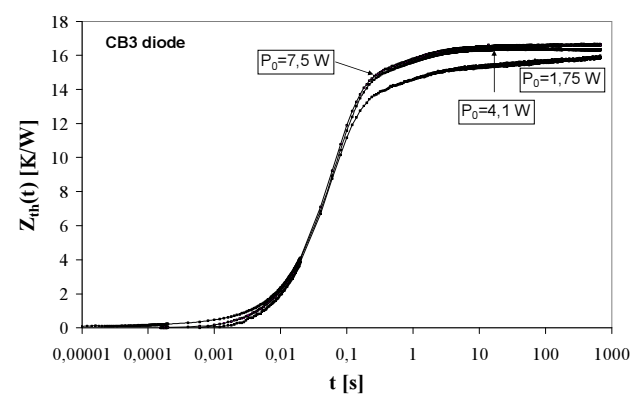

b)

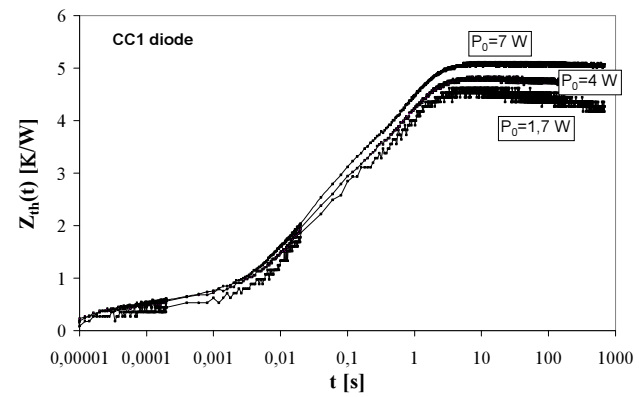

d)

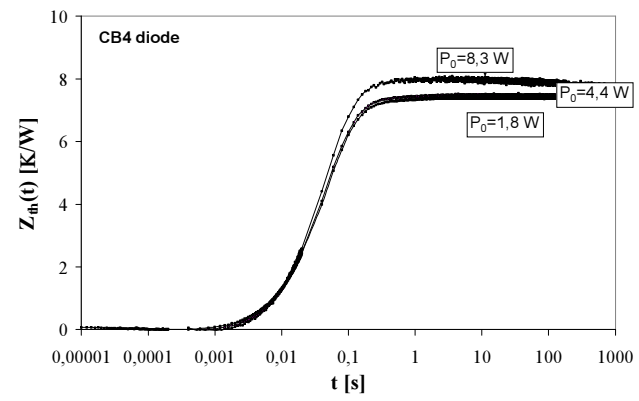

Fig. 6. The measured transient thermal impedance waveforms of the diodes: a) MBR2060CT; b) $\mathrm{CC} 1$; c) $\mathrm{CB} 3$; d) CB4.

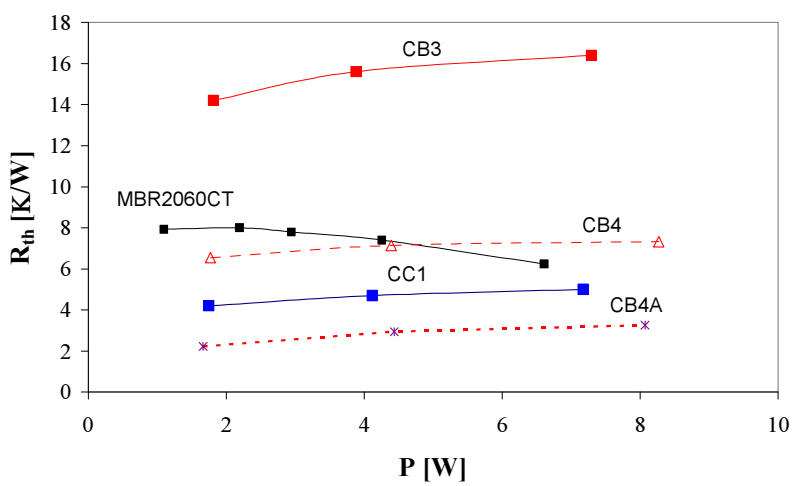

Fig. 7. The measured dependences $R_{t h j-a}(P)$ of the examined diodes. 
Analysing the results of measurements obtained for the tested diodes it can be noticed that the process of heating every diode runs at a different speed. The quickest process is observed for the diode CB4, because after just $0.2 \mathrm{~s}$ the steady state is obtained. The diodes CC1 and CB3 need 4 and 8 seconds to obtain the steady state, respectively. The commercial MBR2060CT diode needs the longest time to obtain the steady state - about 20 seconds. For the MBR2060CT diode there are two visible thermal time constants equal to about $40 \mathrm{~ms}$ and about $2 \mathrm{~s}$. Finally, for the diodes $\mathrm{CC} 1, \mathrm{CB} 3$ and $\mathrm{CB} 4$ the dominant thermal time constants are equal to about $0.76 \mathrm{~s}$, $0.48 \mathrm{~s}$ and $0.87 \mathrm{~s}$, respectively.

Additionally to the thermal time constants, the differences in thermal resistances of the examined diodes are clearly visible in charts of Fig. 6. In Fig.7 the measured dependences of thermal resistance $R_{t h}$ on power $P$ for the tested diodes are shown.

It is clear that the obtained thermal resistances differ from each other even by four times. The range of thermal resistance values is from about 4 to above $16 \mathrm{~K} / \mathrm{W}$. As it can be noticed, an $\mathrm{SiC}$ diode without any package (CC1) has by about $35 \%$ smaller values of $R_{t h}$ than the diode assembled in the complete package (CB4). $R_{t h}$ values of an SiC diode assembled in the complete package are comparable with those of a commercially accessible silicon diode in the TO-220 package. In the case of the commercial silicon diode an increase in power causes a decrease of $R_{t h}$, whereas in all tested $\mathrm{SiC}$ diodes $R_{t h}$ increases with an increase of power.

The two examined devices in the complete packages (CB3 and CB4) are characterized by the thermal resistances of substantially different values. The result of this difference, at the same value of thermal power (equal to about $7.5 \mathrm{~W}$ ) is that the internal temperature in a faultless device reaches about $85^{\circ} \mathrm{C}$, whereas in a defective device it reaches even $145^{\circ} \mathrm{C}$. The observed differences in the values of thermal resistance of tested diodes result most probably from a worse quality of the thermal contact between the DBC substrate and the structure of diode CB4. The differences can be caused by an imperfect mounting process of this device.

In Fig. 7 the results of measurements of thermal resistance for the capsulated structure placed between two water cooling elements (curve CB4A) are additionally marked. It is easy to notice that a change of the way of mounting the examined element caused almost a double decrease in its thermal resistance. This decrease results from the enlarged area of contact between the examined device with the liquid heat-sink and possible efficient heat exchange on both sides of the device case. A certain significance can have also an increase of the pressure between the diode and the heat-sink, causing a decrease of the thermal resistance between the device case and the heat-sink.

It is worth noticing that the obtained results of measurements can be interpreted as the values of thermal resistance between the semiconductor structure and the heat-sink of a fixed temperature. An additional factor that influences the thermal resistance measurements is the quality of connection between the package and the heat-sink.

The measurements of transient thermal impedance of the tested diode (CB4) are also affected by different values of the ambient temperature. In Fig. 8 the waveforms of $Z_{t h}(t)$ of diode operating at the water cooling and two values of temperature of cooling liquid equal, in turn, to $24^{\circ} \mathrm{C}$ and $50^{\circ} \mathrm{C}$, are presented. As one can observe the temperature rise of this liquid causes a small (of about 10\%) increase of the value of thermal resistance of the examined diode, and also shortens the time indispensable to obtain the thermally steady state which does not exceed $1 \mathrm{~s}$.

In order to evaluate the thermal properties of the tested device operating at the free-air cooling, the measurements of waveforms of transient thermal impedance of the diode placed on the heat exchanger, as shown in Fig. 5b, over a wide range of changes of the ambient temperature were performed. During the measurements the examined diode was placed in the thermostat of $39 \mathrm{dm}^{3}$ volume. The results of these measurements are presented in Fig. 9. 
As shown in Fig. 9, a change of the ambient temperature within the range from $24^{\circ} \mathrm{C}$ to $100^{\circ} \mathrm{C}$ causes an increase of the thermal resistance by even about $20 \%$. It is worth paying attention to the results of measurements presented in Fig. 7: the thermal resistance when the diode operates at the free cooling is over three times bigger than that obtained at the water cooling of this device. Simultaneously, extension of the time indispensable to obtain the steady state is visible. This time reaches even $6000 \mathrm{~s}$. In the considered cooling conditions, for the power dissipation in the examined device equal to about $8 \mathrm{~W}$, the internal temperature of the examined device exceeds even $200^{\circ} \mathrm{C}$.

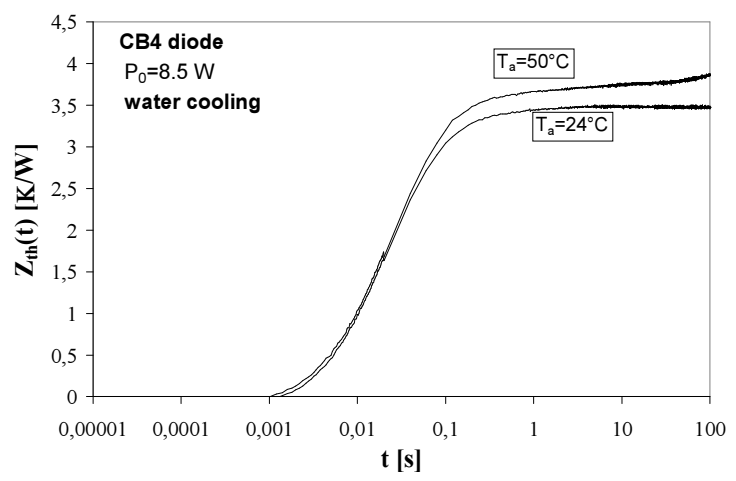

Fig. 8. The measured waveforms of $Z_{t h}(t)$ of the diode CB4 operating at the water cooling and different values of the ambient temperature.

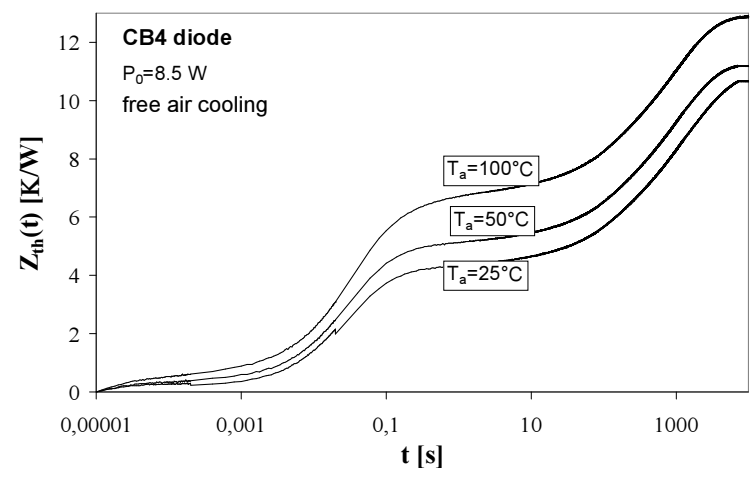

Fig. 9. The measured waveforms of $Z_{t h}(t)$ of the diode CB4 operating at the air cooling and different values of the ambient temperature.

The observed increase of the value of $R_{t h}$ and time indispensable to obtain the steady state result from changing the prevailing mechanism of cooling from the forced one with water to the free one - with air. It is far less effective, but at the same time it is practically more often used and is cheaper.

Considering the error of measurements of the thermal parameters of semiconductor devices, presented - among others - in the papers $[12,21]$ it can be observed that for the measurements of thermal resistance with the employed method, with the applied instruments and in the given conditions of the power supply of the examined diode, it does not exceed $5 \%$. 


\section{Conclusions}

In the paper, the thermal properties of a selected construction of packages of Schottky diodes made of silicon carbide are considered. Using the electrical pulse methods the transient thermal impedance waveforms of the examined devices have been measured.

It results from the performed measurements that the most efficient heat removal is assured by a new construction of the casing devoid of a ceramic lid. Protection of the examined structure with a ceramic lid, which is indispensable for the normal usage of the tested device, causes at least $50 \%$ increase of the thermal resistance. Probably this increase is a result of worse heat convection from the semiconductor structure and worse heat radiation caused by the ceramic lid. In the next version of packages an additional thermally conducted material between the semiconductor structure and the ceramic lid should be added. Emissivity of the ceramic lid should be increased using black paint.

The measured thermal resistance is a growing function of power dissipated in the diode. That confirms that the dominant mechanism of heat removal is conduction, the efficiency of which decreases when the temperature of semiconductor structure rises [5]. The obtained values of thermal resistance of a diode mounted in a new casing are close to the value of this parameter for the diode mounted in the classical TO-220 case. However, the materials used in construction of the new case theoretically make possible operation of the considered diode at the junction temperature of up to even $300^{\circ} \mathrm{C}$ [13].

Apart from evaluation of the thermal properties of the new case of a Schottky diode operating at the ideal cooling of its surface, the influence of the temperature and air cooling on the thermal parameters of examined device were tested. It was shown experimentally that a temperature rise of the cooling liquid caused a slight deterioration of the efficiency of cooling of the examined diode.

The examinations performed at the typically used free cooling showed that even at the ambient temperature equal to $100^{\circ} \mathrm{C}$ in the examined diode the power exceeding $8 \mathrm{~W}$ could be dissipated, and the temperature of the structure would not exceed $200^{\circ} \mathrm{C}$. The presented findings prove that the package for SiC Schottky diodes manufactured at Warsaw University of Technology can be used in high-temperature applications.

\section{References}

[1] Buttay, C., Raynaud, Ch., Morel, H. (2012). Thermal Stability of Silicon Carbide Power devices. IEEE Transactions on Electron Devices, 59(3), 761-769.

[2] Buttay, C., Raynaud, Ch., Morel, H., Lazar, M., Civrac, G. (2011). High-Temperature Behavior of SiC Power Devices. Proc. of 14th European Conference on Power Electronics and Applications EPE2011, 1-9.

[3] Kisiel, R., Guziewicz, M., Szczepański, Z., Król, K. (2010). An Overview of Materials and Bonding Techniques for Inner Connections in SiC High Power and High Temperature Devices. Proc. of ISSE 2010, Warszawa, Poland, 128-130.

[4] Alexakis, P., Alatise, O., Hu, J., Jahdi, S., Ran, L., Mawby, P.A. (2014). Improved electrothermal ruggedness in Sic mosfets compared with silicon IGBTS. IEEE Transactions on Electron Devices, 61(7), 2278-2286.

[5] 5th Generation thinQ! ${ }^{\mathrm{TM}} \mathrm{SiC}$ Schottky Diode IDL02G65C5. Data Sheet, Infineon Technologies, 2013.

[6] APT10SCD120BCT. Data Sheet, Microsemi Power Products Group, 2012.

[7] C3D1P7060Q Silicon Carbide Schottky diode Z-REC Rectifier. Cree Inc., 2015.

[8] Górecki, K., Zarębski, J. (2014). Modeling the influence of selected factors on thermal resistance of semiconductor devices. IEEE Transactions on Components, Packaging and Manufacturing Technology, 4(3), 421-428. 
[9] Blackburn, D.L. (2004). Temperature Measurements of Semiconductor Devices - A Review. 20th IEEE Semicon. Thermal Measur. and Menagement Symp. SEMI-THERM, San Jose, 70-80.

[10] Starzak, Ł., Zubert, M., Janicki, M., Torzewicz, T., Napieralska, M., Jabłoński, G., Napieralski, A. (2013). Behavioral approach to SiC MPS diode electrothermal model generation. IEEE Transactions on Electron Devices, 60(2), 630-638.

[11] Blackburn, D.L., Oettinger, F.F. (1976). Transient Thermal Response Measurements of Power Transistors IEEE Transactions on Industrial Electronics and Control Instrum., IECI-22(2), 134-141.

[12] Górecki, K., Górecki, P. (2015). The analysis of accuracy of the selected methods of measuring thermal resistance of IGBTs. Metrol. Meas. Syst., 22(3), 455-464.

[13] Oettinger, F.F., Blackburn, D.L. (1990). Semiconductor Measurement Technology: Thermal Resistance Measurements, U. S. Department of Commerce. NIST/SP-400/86.

[14] Górecki, K., Zarębski, J. (2014). The influence of the selected factors on transient thermal impedance of semiconductor devices. Proc. of the 21st International Conference Mixed Design of Integrated Circuits and Systems MIXDES, Lublin, 309-314.

[15] Górecki, K., Zarębski, J. (2014). The semiconductor device thermal model taking into account non-linearity and multhipathing of the cooling system. Journal of Physics: Conference Series, 494, 012008, DOI:10.1088/1742-6596/494/1/012008.

[16] Myśliwiec, M., Kisiel, R., Guziewicz, M. (2015). Materials and technological aspects of high-temperature $\mathrm{SiC}$ device packages Reliability. Microelectronics International, 32(3), 143-148.

[17]Székely, V. (1998). Thermal Testing and Control by Means of Built-in Temperature Sensors. Electronics Cooling, 4(3), 36-39.

[18] Szekely, V. (1997). A New Evaluation Method of Thermal Transient Measurement Results. Microelectronic Journal, 28(3), 277-292.

[19] Górecki, K., Rogalska, M., Zarębski, J. (2014). Parameter estimation of the electrothermal model of the ferromagnetic core. Microelectronics Reliability, 54(5), 978-984.

[20] Górecki, K., Zarębski, J., Bisewski, D. (2015). An influence of the selected factors on the transient thermal impedance model of power MOSFET. Informacije MIDEM - Journal of Microelectronics, Electronic Components and Materials, 45(2), 110-116.

[21] Zarębski, J., Górecki, K. (2008). A Method of the Thermal Resistance Measurements of Semiconductor Devices with P-N Junction. Measurement, 41(3), 259-265. 